\title{
EL EDUBLOG EN EL CONTEXTO EDUCATIVO UNIVERSITARIO
}

\section{Edublog in the university educational context}

\section{Carlos Enrique Cabrera}

Instituto Tecnológico de Santo Domingo (INTEC). República Dominicana

Correo-e: carlos.cabrera@intec.edu.do ORCID: 0000-0002-5829-7236

Recibido: 14/4/2019 • Aprobado: 10/6/2019

Cómo citar: Cabrera, C. E. (2019). El edublog en el contexto educativo universitario. Ciencia y Sociedad, 44(3), 7-23. https://doi. org/10.22206/cys.2019.v44i3.pp7-23

\section{Resumen}

Este artículo se centra en las tecnologías de la información y la comunicación (TIC), específicamente en los weblogs: nacimiento y evolución, estructura, tipos y características; las particularidades del post como unidad de información/ narración y la inserción de esta herramienta social en la llamada blogosfera. El interés principal se dirige hacia el edublog y sus grandes posibilidades para favorecer y fortalecer el proceso de enseńanza aprendizaje, especialmente en la educación superior y universitaria, donde se analiza no solo lo que puede brindar la implementación de weblogs a los alumnos, sino también a los propios profesores. En las conclusiones, se sostienen los efectos positivos de los blogs implementados dentro del marco de una pedagogía constructivista, así como la necesidad de favorecer y potenciar su uso, análisis y estudio en la universidad, tanto por parte de los docentes como de los discentes y autoridades académicas.

Palabras clave: tecnologías de la información y la comunicación; enseñanza multimedia; constructivismo; enseñanza superior.

\begin{abstract}
This article deals with Information and Communication Technologies (ICT), and specifically with weblogs: birth and evolution, structure, types and characteristics, the particularities of the post as an information / narrative unit and the insertion of this social tool in the so-called blogosphere. The focus is on the edublog and its great possibilities to promote and strengthen the teaching-learning process, specifically in higher education and university where it is analyzed not only what the implementation of weblogs can provide students but also the teachers themselves. In the conclusions, the positive effects of the blogs implemented within the framework of a constructivist pedagogy are sustained as well as the need to favor and promote its use, analysis and study in the university, both by teachers and students and authorities academic.
\end{abstract}

Keywords: Information and communication technologies; multimedia teaching; constructivism; higher education. 


\section{El edublog en el contexto educativo universitario}

Leyendo y escribiendo blogs, blogeando, los estudiantes pueden iniciar un viaje de autodescubrimiento intelectual.

Miguel A. Martín Sánchez y Laura Alosnso Díaz

Quien escribe en una bitácora se está convirtiendo en editor y su producto puede tener los más inimaginables destinos.

Lorenzo García Areito

\section{Introducción}

Las tecnologías de la información y la comunicación (TIC) se han constituido, en unas cuantas décadas, en un elemento indispensable en el desenvolvimiento y desarrollo de las sociedades contemporáneas, cimentadas en el conocimiento, en la información y en su rápida administración y diseminación. Es así como hoy resulta imposible encontrar un solo ámbito de la sociedad —incluido el de la educación - en el que las TIC no se manifiesten de forma determinante y fuertemente transformadora (Manrique Maldonado, 2015). Esto ha llevado a hablar de la "revolución digital", que marca asimismo el comienzo de la llamada "sociedad de la información y sociedad del conocimiento”. En palabras de Finquelievich y Prince (2008), citado por Maenza (2011, p. 43) se entiende esta como un:

estadio económico social cuyas acciones de supervivencia y desarrollo están caracterizadas por la capacidad potencial de sus miembros (personas y organizaciones) de hacer un uso evolutivo (extensivo, intensivo y estratégico) de las TIC para interconectarse en red entre ellas (y con las cosas) de modo convergente, ubicuo, instantáneo y multimedial; a fin de obtener y compartir información, almacenarla, procesarla, analizarla y/o distribuirla a voluntad (Finquelievich y Prince, 2008).

Cabero Almenara (2000) describe las TIC — diferenciándolas oportunamente de las tecnologías tradi- cionales de la comunicación e información-como aquellas "que giran en torno a tres medios básicos: la informática, la microelectrónica y las telecomunicaciones. Este "giro" se hace, nos dice el autor, no de forma aislada, sino interactiva e interconexionada, "lo que nos permite conseguir nuevas realidades comunicativas y potenciar las posibilidades que pueden tener de forma aislada”. (p. 1)

Asimismo, Cabero (2000) señala como características definitorias de las TIC las siguientes: inmaterialidad, interactividad, interconexión, instantaneidad, digitalización, amplio alcance (campos cultural, económico, educativo...); una mayor influencia sobre los procesos que sobre los productos (los individuos tienen un mayor protagonismo en la creación de conocimiento de forma colectiva); innovación, diversidad (útiles para la ejecución de más de una función) y tendencia a la automatización.

En el dinámico y cambiante universo de las TIC confluye un amplio conjunto de recursos tecnológicos digitales (hardware y software), que permiten procesar, administrar y compartir grandes volúmenes de información a distancia, en tiempo récord y con gran fidelidad y confiabilidad, así como en los más disímiles formatos: texto, imagen, sonido. Se trata, además de la computadora de mesa (PC), de dispositivos digitales (digital device) de más reciente aparición como los teléfonos, relojes y televisores inteligentes, tabletas, laptops, reproductores portátiles de audio y video o consolas de videojuegos, y como señala Belloch Ortí (s.f.) de los servicios y funcionalidades telemáticos que ofrecen las redes globales y públicas (Internet) o locales y privadas (Intranet): páginas web (Word Wilde Web con descarga de texto, imagen, sonido, software), correo electrónico, telnet, foros de discusión, transferencia de archivos (FTP) audioconferencia y videoconferencia, chats o charlas (IRC-Internet Relay Chat), así como la realidad virtual (3D) y los simuladores.

Entre estos elementos — conformadores del mundo de las TIC y específicamente de las herramientas de la Web 2.0, surgida en la década del 2000_, se 
encuentra el que es objeto preferente de estas páginas: los weblogs, blogs o bitácoras, que trataremos con amplitud, viendo sobre todo su inserción en un ámbito tan sensible y vital de la vida social como es el de la educación en general, y más específicamente el de la educación superior o universitaria. Inserción que, como señalan Aguded y otros (2010a y 2010b), citado por Cabero Almenara, López Meneses y Jaén Martínez (2013, p. 46), demanda una ruptura del modelo tradicional metodológico centrado en el docente (transmisión de contenidos, su reproducción por los alumnos, la lección magistral y el trabajo individual) "al mismo tiempo que supone un avance hacia la calidad de la Educación Universitaria" (Aguaded et. al., 2010a y 2010b).

\section{El origen de los blogs}

El nacimiento del weblog se produce a la par que el de la propia red y se debe al británico Tim Berners Lee, quien creó en Ginebra (Suiza), en enero de 1992, el sitio What's new in '92, con objeto de divulgar las novedades del proyecto en que trabajaba y del que es padre indiscutido: el Word Wide Web. Pero el término weblog fue acuñado por el escritor norteamericano (gran conocedor de la red) Jorn Barger en diciembre de 1997 y en su página Robot Wisdom (Méndez García, 2005). Barger, junto a Dave Winer, Lawrence Lee y Cameron Barret, habían puesto en marcha en 1996 los primeros weblogs tal como los conocemos hoy, y desde este momento el número de los mismos se vio disparado de forma espectacular. Barrer utilizó el término web log, separado, haciendo referencia a un diario en línea, publicado en Internet. "weblog", "anotar (sobre) la red" (logging the web). Posteriormente, las dos palabras (web y $\log$ ) se fusionaron, dando lugar a "weblog". Peter Merholz (1999) dividió el término en "we blog" en el subtítulo de su página Peterme, creando así la versión abreviada - y que resultaría más comúnmente aceptada para hacer referencia a la singular herramienta web- y el verbo que significa publicar un post. (Dellepiane, s.f; Cervera, s.f.)

\section{El blog definición y concepto}

La herramienta web que estudiamos — de gran difusión y aceptación en la contemporaneidadse denomina tanto weblog, blog, como cuaderno de bitácora o simplemente bitácora, en español. La Real Academia Española (2005), en su Diccionario panhispánico de dudas propone, además de su propia y particular definición, estos otros términos: "ciberbitácora” y "ciberdiario" y explica el porqué: "Para hacer más explícita su vinculación con Internet (como hace el inglés weblog)."

Pero si variadas son las denominaciones del weblog, todavía más lo son las definiciones que pueden salirnos al paso de la popular herramienta digital, cada una de ellas elaborada desde una particular perspectiva, haciendo énfasis en un específico aspecto. Así, Gewerc Barujel (2005) propone la siguiente:

Los weblogs o bitácoras son un formato de publicación en línea que se caracteriza por la configuración cronológica inversa de las entradas y en el que se recogen, a modo de diario, enlaces, noticias y opiniones de autoría mayoritariamente individual con un estilo informal y subjetivo. (p. 13)

Por su parte Huffaker (2005) y Guenther (2005), citados por Aguaded Gomez y Lopez Meneses (2009, p. 167), lo definen asi: "El blog es una publicación en red que permite a los usuarios crear y editar el contenido de una página web con un mínimo de conocimientos técnicos (Huffaker, 2005)". "y: [los blogs] generalmente, se componen de una página de entradas que son accesibles por el público, dispuestas cronológicamente en orden inverso, y que presentan enlaces a otros blogs o sitios web (Guenther, 2005)".

Por su parte, Contreras Contreras (2004, pp. 3-4) ofrece varias definiciones de weblog de diversa filiación y procedencia. Resalta la de Winner, claramente focalizada en los aspectos técnicos: "Un weblog es una jerarquía de textos, imágenes, objetos multimedia y datos ordenados cronológicamente que 
pueden ser vistos a través de un navegador. (Winner, 2003)”.

Planteada desde otro ángulo, la definición de Walker (2003) ofrecida por Contreras Contreras (2004) resulta más estructural:

Blog es un sitio web frecuentemente actualizado que consiste en accesos fechados cronológicamente en orden inverso de tal forma que los mensajes más recientes aparecen primero. Generalmente los blogs son publicados por individuos y su estilo es personal e informal. (p. 3)

Como vemos, es claro que el aspecto "disposición cronológica en orden inverso" de los post es una característica esencial y definitoria de los blogs. Pero ¿qué otras poseen o podemos atribuirles con buen criterio?

\section{Características esenciales de los blogs}

Los weblogs, blogs o cuadernos de bitácoras o bitácoras son técnicamente páginas web que poseen unas muy específicas y bien diferenciadas particularidades estructurales y funcionales, propias de la web 2.0. o "web social", surgida, como ya señalamos, en la década del 2000. Ruiz Franco y Abella García (2011) explican cómo la web 2.0 pasó "de las páginas web que eran únicamente de lectura y se desarrollaban en entornos planos de observación unidireccional (Web 1.0) a la combinación de lectura y escritura con una gran fluidez de información" (p. 56). Asimismo, estos autores señalan algunas de las características más destacadas que introduce la "Red social", a todas luces consustanciales a los weblogs, que no por pura coincidencia surgen en la misma década:

fácil acceso, el papel activo que los usuarios tienen al poder controlar los datos e información, la constante actualización de contenidos (Maloney, 2007) y las posibilidades para crear, modificar y compartir contenidos con los demás (Alexander, 2006). (...) la interacción y colaboración entre los usuarios, y la elaboración y construcción de un nuevo conocimiento (De Haro, 2010a). La conversión del usuario en lector y escritor de contenidos con un papel activo (López Meneses, 2009) en entornos de comunicación e interacción bidireccional y multidireccional (Lozano, 2008). (Ruiz Franco y Abella García, 2011, p. 56)

Por su parte, Orihuela (2006) precisa cómo Internet ha posibilitado la distribución y publicación de información y opiniones, al tiempo que la formación de comunidades y espacios de trabajo cooperativo ha contribuido "a potenciar la interacción social mediante los chats de texto, audio y vídeo, y la mensajería instantánea” (p. 66). Todo lo cual — señala el autor-, quedó perfectamente asimilado en los weblogs que "facilitan la publicación de información y opiniones, distribuyen información mediante fuentes RSS, generan y se integran en comunidades virtuales y potencian la interacción social”. (p. 66)

Así pues, los blogs o bitácoras (administrados por una persona a la que suele denominársele bloguer o bloguero), se presentan como una herramienta social fácilmente modificable y actualizable, que posibilita la interacción con el usuario (internauta) a través de los comentarios a las entradas (o posts) que se van sumando al weblog en riguroso orden cronológico inverso.

González Sánchez y García Muiña (2009) señalan cómo el notable crecimiento de los blogs en la red se ha debido en gran medida a que poseen:

un mayor dinamismo que las páginas web, son más estructurados que las listas de distribución y tratan los temas de una manera más efectiva que los foros (Marzal y Butera, 2007). Además, en muchas ocasiones contienen elementos o están interconectados con los instrumentos anteriores o con otros blogs (p. 138).

Estalella (s.f.) destaca este carácter conectivo del blog, que es justamente la característica - como veremos más adelante- que hace posible la conformación de la llamada blogosfera. 


\section{Anatomía y estructura de un blog}

Los blogs están conformados estructuralmente por dos zonas claramente diferenciadas: una interna, de gestión (el panel de administración), a la que solo accede el administrador o coadministradores, y una externa, pública (la interfaz de usuario) que es la que navegamos los usuarios de la red. Estas dos zonas están conformadas a su vez por diferentes elementos que cambiarán de acuerdo a la plataforma en la que se implemente el blog: WordPress, Blogger, Medium, Overblog, Obolog, etcétera. Hoy existe, una gran variedad en la estructura de los weblogs, incluso dentro de una misma plataforma. Así, por ejemplo, Blogger amplió en 2011 su oferta de plantillas y además las enriqueció haciéndolas más versátiles con las llamadas plantillas dinámicas, que pueden adoptar diferentes formatos según los seleccione el usuario: Mosaic, Classic, Flipcard, Magazine, Sidebar, Snapshot y TimeSlide.

Tradicionalmente, la interface de usuario ha estado conformada (seguimos en Blogger) por los mismos invariables elementos: cabecera (donde van el título y subtítulo del blog), columna principal o cuerpo central (donde se insertan los posts y los elementos que lo acompañan), barra lateral de navegación - con gadgets - y pie de blog. En la parte interna (privada), encontraremos la denominadas área de creación (permite escribir los artículos y moderar los comentarios, etc.), área de configuración (permite modificar los parámetros generales del blog y añadir otros editores) y área de personalización (permite cambiar la apariencia del blog, eligiendo entre las diferentes plantillas facilitadas).

Apoyándonos en trabajos anteriores (Fumero, s.f.; Ramírez Sánchez, 2010; Ruiz Blanco, 2009), nos interesa mostrar en este apartado, sobre todo, la estructura operativa y funcional del blog, aquellos componentes que independientemente de la plataforma que se use se consideran de manera consensuada definitorios de la herramienta de comunicación y administración de contenidos (Content Management System o CMS, en sus siglas en inglés) que es el weblog
(Ramírez Sánchez, 2010). A continuación, dichos elementos:

-Anotación. Artículo o posts. Los posts son cada una de las entradas del blog. Se disponen en el centro del mismo (configuran realmente su cuerpo) en orden cronológico inverso y como tal elemento HTML podrán contener texto plano, imágenes, sonido o video. Cada uno de los post estará constituido básicamente por: un título, la fecha de creación (o la de la última actualización) y los enlaces o hipervínculos (biper links). Fumero (s.f.) señala que "La presencia de esos enlaces ha sido considerada la característica clave [del blog], puesto que resultan fundamentales para la existencia de las conversaciones, elemento básico en la dinámica de la blogosfera." (p. 201).

Cada uno de los posts incluirá asimismo un enlace permanente (permalink) que permitirá que cualquier internauta pueda enlazar ese artículo concreto y no al blog en su totalidad. Este permalink "resulta asimismo fundamental para la estructura y la dinámica (...) de la blogosfera”, ya que al ser una dirección única adjudicada a cada uno de los posts, los dota de identidad propia, de suerte que pueden "ser referenciados desde cualquier otro sitio mediante el URL correspondiente a ese permalink, enlace permanente o, para algunos puristas, enlace fijo". (Fumero, s.f., p. 202) Para Ruiz Blanco (2009) "Este enlace debe permanecer en el tiempo ya que, si no, quedaría obsoleta en el futuro toda referencia de otros autores." (p. 192).

-Comentarios. Los comentarios son igualmente parte esencialísima de los weblogs. Constituyen sin duda un claro elemento definitorio y diferenciador de estos, en tanto en cuanto garantizan la interactividad con los usuarios, el diálogo y el debate en la red y en la blogosfera. Para comentar en un blog, se les exige a los internautas una identificación mínima (nombre, correo-e y una url). Tanto los comentarios de los internautas-lectores como las respuestas del autor pueden ser recuperados a través de los debidos enlaces recogidos en una sección del post. 
-Categorías. Las categorías permiten al autor del blog agrupar (o catalogar) los posts por su tema o contenido. Así, una entrada o post puede aparecer bajo más de una categoría. Las categorías permiten almacenar, ordenar, jerarquizar y administrar el contenido del weblog, haciendo más fácil la recuperación posterior por parte de los usuarios de aquellos posts o entradas que ya han desaparecido de la página principal. Hoy las categorías (más genéricas) se han visto desplazadas por el uso de las etiquetas o tags, que permiten una mayor concreción y especificidad en la expresión de los contenidos de los archivos del blog. Un post puede quedar adscrito a la categoría "Blog" y a las siguientes etiquetas: "categoría, etiqueta, blog, post, redes sociales, social media”. Navarro (2017) señala cómo en WordPress hay tanto categorías como etiquetas, para gestionar el contenido de los posts; mientras que en Blogger, por el contrario, solo se utilizan las etiquetas. Asimismo, señala el autor, cómo las categorías pueden emplearse como etiquetas, mientras que las etiquetas no pueden usarse como categorías.

-Los trackbacks y los pingbacks. Son herramientas de comunicación que permiten la generación de referencias cruzadas entre los distintos blogs, dando a conocer al bloguer, mediante un aviso "ping", que suele alojarse en los comentarios, quién ha enlazado o citado uno de los artículos de su propio blog. El trackback es igual que el pingback, pero con la diferencia de que el primero es un proceso manual (el bloguero avisa que está enlazando un artículo determinado) y el de los pingbacks, automático: el aviso del enlace o cita es generado por el propio sistema. Aunque esta tecnología está totalmente integrada en WordPress, no es exclusiva de esta plataforma de servicios de alojamiento de blogs.

-Blogroll o blogs favoritos. Los blogrolls no son más que un listado de enlaces de weblogs, ya afines a los intereses del propio autor (y que visita con asiduidad) o simplemente gestionados por amigos o cercanos.

-Sindicación de contenidos (RSS). Los archivos Rich Site Summary (RSS), popularmente conocidos como feeds, son un claro elemento diferenciador de los medios sociales surgidos con el advenimiento de la web 2.0. Estos archivos permiten una actualización permanente por parte de los usuarios de los contenidos del blog (de las nuevas entradas) de forma en extremo cómoda, sin tener que acceder al mismo, lo cual supone un gran ahorro de tiempo. Generados de manera automática por el CMS, exigen que los usuarios utilicen algún agregador de noticias of feed reader para poder suscribirse al weblog. Con este fin, la mayoría de weblogs incorpora botones con algunos de los formatos más usuales para sindicación de contenidos, perfectamente reconocibles mediante las abreviaturas XML, RSS, RDF, o ATOM.

-Archivos del blog. A medida que se van publicando los posts y estos dejan de mostrarse en la página principal, podremos encontrarlos en "Archivos del blog", situado muchas veces en la barra lateral. Este archivo puede ser ordenado en base a diferentes opciones, pero siempre -como es propio de los blogs-, bajo un criterio rigurosamente cronológico: artículos recientes, por semana, por meses o por ańos. No obstante, también se puede implementar un archivo de los post más leídos o más visitados. El número de posts contenido en cada apartado se mostrará de forma visible en la página.

-Búsqueda. La mayoría de blogs incluyen una casilla o caja con esta función de búsqueda, indispensable para la localización — por temas o palabras clavede los posts de nuestro interés dentro del blog. Por lo general realiza su rastreo dentro del mismo blog, pero en muchos casos la búsqueda puede ampliarse a toda la red. El gadget buscador suele situarse junto al título del blog, o al inicio de la barra lateral.

\section{Creación y administración de un blog}

Existen, como ya señalamos más arriba, numerosas plataformas de Internet que permiten crear y administrar un blog. Entre las más conocidas y populares se encuentran: WordPress, Blogger, Obolog, Medium y Wix. Todas ellas son gratuitas y no exigen un gran 
conocimiento técnico (diagramación, HTML, CSS, flash) para llevar a cabo la tarea de creación del weblog; que será tan sencilla como gestionar una cuenta de correo electrónico. Sin duda esto ha sido decisivo en la popularización de la herramienta y en su uso cada vez más frecuente en las aulas.

Para crear el weblog (hablamos de Blogger) tan solo hay que realizar estos sencillos pasos: acceder a Google y sacar una cuenta (es indispensable), tras lo cual podremos acceder a Blogger y su escritorio de gestión. Aquí hacemos clic en "Blog nuevo". Escribimos un nombre para el mismo, elegimos una dirección URL (nuestro nombre o nombre del blog. Blogspot.com) y una plantilla de nuestro agrado, entre las muchas y muy variadas ofertadas por la plataforma. Hacemos clic en "Crear blog". (Por supuesto Blogger tiene una política de contenido y unas condiciones del servicio que debemos cumplir).

Una vez creado el blog, deberemos gestionarlo desde el "panel de administración" de acuerdo con nuestras preferencias. Así, podremos determinar quién puede editarlo (autores o coadministradores que elijamos), controlamos el acceso al blog (quién puede leerlo) haciéndolo público o de acceso restringido, privado. Todo esto se hace desde el "área de configuración". De igual modo (desde el "área de edición". Entradas) podremos borrar o reescribir los artículos, moderar los comentarios de los lectores, coordinar intervenciones, etcétera. También variar el diseño del blog (cómo queremos que se vea en la pantalla del ordenador o del móvil) desde el "área de personalización" (tema en Blogger).

\section{Tipos de blogs y características}

Clasificar los blogs, tipificarlos o inscribirlos en categorías no es tarea sencilla. Al igual que vimos con la definición, existen diferentes taxonomías, cada una fundamentada en un criterio específico. Maenza (2011, p. 192) muestra numerosas y variadas clasificaciones: la de Bausch, Haughey y Hourihan (2002) que se basa en el formato y el contenido; la de Fumero (2005), elaborada con base en tres criterios: orden social, orden estructural y orden informacional; así como la de Orihuela (2006), que en el libro La revolución de los blogs despliega una extensa tipología formada por cuarenta y una clases de blogs organizados según el tema o el contenido. Tras este recorrido, Maenza (2011) ofrece su propia y particular clasificación, "una mínima taxonomía tendiente a diferenciar categorías según: el autor, la tecnología o el contenido y la especificidad o temática" (p. 191). Apoyándonos en Maenza, veremos muy por encima, de forma casi estrictamente enumerativa, los diferentes tipos de blogs, para centrarnos con posterioridad en la clasificación de los blogs educativos o edublogs, tema focal de este trabajo.

Según Maenza, los blogs podrán ser: personales, corporativos o institucionales. Quedan incluidos aquí los weblogs profesionales pertenecientes a artistas, escritores, políticos, etcétera.

De acuerdo a la tecnología empleada o el contenido transmitido, serán:

Fotologs o drawlogs (blogs de fotos y dibujos), audioblogs y videologs (blogs de video y audio).

Por el tipo de medios de comunicación, tendremos: Microblogs (Twitter fue la plataforma pionera en brindar este servicio) $y$ Moblogs (blog que se maneja desde un dispositivo móvil). Los servicios de microblogging se dividen en verticales y horizontales. Los verticales permiten crear redes de usuarios de carácter público o privado. Específicamente en educación son muy conocidos Twiducate y Edmodo. En los servicios horizontales - a los que pertenecen el mismo Twitter y Plurk-, la incorporación del usuario se hace a una red ya creada.

De acuerdo con la especificidad o temática existe una gran variedad de blogs, por no decir una auténtica marańa o laberinto de ellos, puesto que el contenido de los mismos se extiende por todas las parcelas del saber y del quehacer humano. Martín Sánchez 
y Alonso Díaz (2008) hacen un recorrido rápido por este laberinto que comprende desde los weblogs de los grandes medios de comunicación de masas, hasta los de ficción (blogonovelas), pasando por los humorísticos, los deportivos, los corporativos e institucionales, los políticos, los de viajes, los que hablan sobre ellos mismos (metablogs), y, por supuesto, los centrados en la educación y sus procesos, los edublogs, que por ser el objeto central de este trabajo analizaremos con detenimiento más adelante.

\section{La blogosfera. El blog como elemento de comu- nicación e intercambio en la web}

Gascueña (s.f.) señala que el concepto de blogosfera nació en septiembre de 1999, cuando Brad L. Gram en su weblog The Bradlands propuso, irónicamente, entre otros términos asociativos (blogiverse, blogmos...) referidos al mundo del weblog, el término Blogosphere. Lo revive en 2002 el novelista estadounidense William Quick, en su blog Daily Pundit, cuando lo usa para designar a un conjunto de blogs que recogen noticias, informaciones y opiniones sobre la segunda Guerra del Golfo, llamados Warblogs.

Maenza (2011) sostiene que la blogosfera o blogósfera es un conjunto de blogs agrupados por algún criterio concreto, tal como la localización, la temática o el idioma, pudiéndose hablar así de la blogósfera literaria, de la política, o de la blogósfera hispana. Por su parte Estalella (s.f., p. 27) asume la visión de Efimova et al., (2005): "La blogosfera no es simplemente el conjunto de blogs y sus contenidos, sino justamente todo eso que está entre ellos: las conexiones, esas sutiles interacciones que son su esqueleto. (...). (Efimova et al., 2005)."

Hablar de blogosfera supone, pues, hablar del blog no ya como un ente individual y aislado, sino como un ente social, asociativo, con una dinámica colectiva, participativa, abierta a la red e interconectado "con sus lectores, con otros blogs y sus autores, con sitios institucionales, iniciativas colectivas, etc." (Estalella, s.f., p. 27).

Gómez Villalta (2012), por su parte, ve la blogosfera como una rica base de datos abierta a la labor investigativa:

La blogosfera, por tanto, es la colección o universo de blogs, que puede ser concebida como una base de datos no estructurada de abundante contenido con diferentes temáticas y que ofrece información sobre la percepción y opinión de la ciudadanía sobre diferentes tópicos, y por consiguiente, puede ser considerada un potencial espacio de investigación. (p. 4)

\section{El artículo o post como unidad de información/ narración}

Los post, publicaciones, artículos o entradas son sin duda la parte central y más importante de los blogs que, como hemos referido, operan como herramientas de comunicación e intercambio de contenidos en la red. Los posts estarán constituidos, estructuralmente, por los siguientes elementos fijos, que proporciona la propia plataforma de servicios de alojamiento:

1) Fecha de publicación.

2) Espacio para el título.

3) Espacio para el contenido, que puede ser texto plano, imagen, enlaces o recursos multimedia: vídeos, música, presentaciones, etcétera.

4) Autor o quien publica o sube el post al blog y todas los elementos o botones de conectividad que enlazarán al correo electrónico y redes sociales, etcétera, para compartir el post.

5) Cuadro para insertar comentarios. (Opcional).

6) Etiquetas o tags que permiten la organización temática por palabras clave. 
Por otra parte, asociado a cada post, encontraremos los siguientes elementos (de los que ya hemos hablado en páginas anteriores): un permalink (enlace permanente generado por la propia plataforma), un enlace a los comentarios y un enlace con la dirección necesaria para realizar una traza o referencia inversa (trackback). Estos dos últimos enlaces estarán asociados a un contador del blog.

Además de estos elementos proporcionados por el propio software, debemos hablar de la configuración del post como entidad intelectual y comunicativa, es decir, del post como la unidad de información/narración del blog, aspecto este sin duda de gran relevancia en el uso educativo de esta versátil herramienta de la web 2.0.

Consideremos, en primer lugar, la redacción del post en texto plano. Lo primero que debemos tener presente a la hora de redactar un post, es que no es igual la escritura en la red que en un material impreso en papel de lectura secuencial, esto por las especificidades de lo digital e hipertextual y porque el lector de la red (el internauta, destinatario del texto) es un lector multitarea, sujeto a múltiples reclamos.

Valero (2007; 2009), Villarejo (2014) y Thiefels (2018) muestran una serie de características que deben cumplir los posts para ser efectivos. Señalan estos autores cómo además de ser breves, ágiles, ligeros, deben estar dotados de títulos atractivos, capaces de captar la atención del lector, y que asimismo sean lo suficientemente significativos como para recoger el contenido del post o sintetizar la idea principal de este. El tema del post deberá estar debidamente delimitado, y se desarrollará — con ideas principales y secundarias en armoniosa progresión lógica- en tres apartados claramente diferenciados: introducción, desarrollo y conclusión. Estos apartados deberán señalarse con sus correspondientes epígrafes o subencabezados para facilitar la lectura y la comunicación.

Esencial asimismo en un post es la división visual del contenido, lo cual se logra (Valero, 2007) te- niendo siempre en cuenta el uso de los siguientes elementos:

- Separación del texto en secciones tituladas con letra de mayor tamaño y si es preciso, numeradas.

- Introducción de viñetas, bullets y o números para las listas de enumeraciones siempre que haya una cantidad abundante de ítems.

- División del texto en párrafos homogéneos y no muy extensos, elaborados con un lenguaje preciso y claro, sin adornos innecesarios ni superfluos. Es siempre aconsejable tratar de usar frases escuetas $\mathrm{y}$ cortas.

- La letra debe tener un tamaño legible y con un interlineado amplio.

- El párrafo no se justifica (se alinea a la izquierda), pues esto produce huecos grandes en el texto y no favorece la legibilidad en pantalla. El párrafo se marca dejando dos espacios entre unos y otros. Se trata del párrafo sin sangría, llamado párrafo bloque.

- Destacar las frases importantes con letra negrita o cursiva, pero nunca con subrayado para que no se confundan con los enlaces hipertextuales.

Los enlaces hipertextuales añaden información adicional al post (remiten directamente a las fuentes de la información enlazadas) sin alargar el contenido visual del mismo, preservando por tanto la ligereza y la agilidad del post. (Internet aula abierta 2.0, s.f.)

Podremos asimismo añadir al cuerpo del post imágenes y elementos multimedia en diferentes formatos (gráficos, fotos, audio y video) que aportan información muy potente y atractiva. Las imágenes deben ilustrar el contenido y no ser un mero adorno decorativo, ser accesorias o responder a un simple capricho del bloguero. Tanto estas como el contenido multimedia deben hacer más comprensibles y asimilable el sentido del post. (Valero, 2009). 
Thiefels (2018) señala como pueden asimismo añadir valor al contenido y servir para separar los párrafos del post. Por otra parte es claro que las imágenes llamativas y de buena resolución contribuirán de forma decisiva a captar la atención de los lectores.

Por último, las actividades interactivas que podemos incluir también en los post son propias de los blogs educativos o edublogs, tema central de este trabajo. Estas actividades permiten, entre otras cosas, la interacción con los estudiantes y realizar un seguimiento de su rendimiento académico. Suponen asimismo un fuerte incentivo y una clara motivación para estos. Como los gestores de blogs (Blogger, WordPress) no incluyen herramientas de esta naturaleza, a pesar de su indiscutible atractivo, su uso no está hoy desafortunadamente muy generalizado (Valero, 2009).

\section{El Edublog. El blog como herramienta de ense- nanza y aprendizaje en la docencia universitaria}

\section{El edublog. Definición e historia}

Los edublogs nacen de la composición entre education y blog. Lara (2005) los define como "aquellos weblogs cuyo principal objetivo es apoyar un proceso de enseñanza-aprendizaje en un contexto educativo. (...) Tanto la educación como los weblogs comparten una característica fundamental: ambos conceptos pueden definirse como procesos de construcción de conocimiento." (p. 3)

Martín Sánchez y Alonso Díaz (2008) ofrecen una más completa definición: "La Education+blogs o edublogs son los weblogs orientados al aprendizaje y la educación que implementan recursos para las comunidades de estudiantes, alumnos y profesores por medio de un sistema de publicación en red interactivo. (Lara, 2005; Castańo y Palacio, 2006)". (párr. 54)

Maenza (2011), Martín Montilla y Montilla Coronado (2015) hacen un recorrido por la historia del edublog y su desarrollo. Los primeros edublogs, nos dicen estos autores, nacieron en los ambientes educativos anglosajones en la década del 2000, específicamente en Inglaterra y Estados Unidos, con iniciativas como el portal británico Schoolblogs.com que funciona desde 2001 y el grupo Education Bloggers Network, asentado en Estados Unidos. Uno de los mayores apoyos al afianzamiento de los edublogs en la educación superior (tanto entre alumnos como profesores e investigadores) se produjo en la Universidad de Harvard (Facultad de Derecho, 2003), por iniciativa de Dave Winer. Otras universidades norteamericanas se sumaron rápidamente a la iniciativa: Drake University, Florida University o la Universidad Californiana de Los Ángeles (UCLA). Pronto vinieron los concursos internacionales para destacar los más relevantes edublogs (Edublog Awards 2004), así como los congresos internacionales (en 2008 el III Encuentro de Edublogs, Santiago de Compostela, Espana y en agosto de 2008 el III Encuentro Mate \& Blogs: Jornada en Educación y TIC, en Rosario, Argentina), todo ello acompañado por un creciente interés por el tema blogs y educación por parte de académicos y estudiosos, y el consecuente incremento de los trabajos de análisis e investigación publicados puntualmente en revistas especializadas de educación y de nuevas tecnologías.

\section{Características de los edublogs}

Molina Aventosa, P., Valenciano Valcárcel, J., y Valencia-Peris, A. (2015) destacan cómo "El blog es un recurso ampliamente utilizado en el ámbito de la Educación Superior, en sus diferentes ramas de conocimiento y en el contexto internacional (Cabero, López y Ballesteros, 2009; Gallego, Martín-Cuadrado y Cacheiro, 2010; Sim y Hew, 2010; Williams y Jacobs, 2004)". (p. 17)

La popularización de las aplicaciones didácticas de los blogs se debe, con toda certeza, a su sencillez de implementación y manejo frente a la edición de páginas web, así como a su interactividad y la posibilidad de añadir contenidos multimedia o enlazar otras fuentes de información. Además de estas 
prestaciones técnicas, está el ya señalado fuerte carácter dialógico de los mismos (Fernández, 2010, citado por Molina Alventosa y Valenciano Valcárcel, 2015).

Pero en última instancia, el uso de este recurso de comunicación en la educación superior debe basarse esencialmente en sus beneficios sobre el proceso de enseńanza aprendizaje, debidamente enmarcado este, como señalan numerosos autores (Duart y Lupiáñez, 2005; Ruiz Franco y Abella García, 2011; Delgado, Trujillo Torres, Lorenzo Martín y Pérez Navío, 2011; Hernández Requena, 2008; Fernández Rodicio, 2010; Chávez y Grisolía, s.f.; Lara, s.f.) en un modelo pedagógico constructivista asociativo.

Los edublogs, empleados tanto por profesores como por los alumnos, pueden servir de apoyo a las clases presenciales, así como de complemento de entornos virtuales de aprendizaje o plataformas de e-learning. Asimismo, se adaptan "a cualquier disciplina, nivel educativo y metodología docente." (Lara, 2005: 3). En efecto, Su uso puede ser implementado tanto en la educación preuniversitaria (primaria, secundaria, bachillerato) como en la universitaria, y en esta, tanto a nivel de grado, de posgrado y maestría como de doctorado. Maenza (2011) señala: "la mayor cantidad de weblogs educativos son dirigidos a la enseñanza secundaria, mientras que en la Universidad existe un considerable número de casos que son utilizados en los cursos de programas de maestría y doctorados" (p. 197). De acuerdo con González y García (2010), citado por Chacón Ortiz (2017), en verdad, "considerando la gran cantidad de instituciones de educación superior que existen hoy día, los blogs no son una herramienta común en la educación universitaria” (p. 55).

\section{Los diferentes tipos de edublogs}

Los edublogs pueden clasificarse de acuerdo a diferentes criterios, fijando tipos y subtipos. Uno de los criterios clasificatorios se basa en quién los implementa y mantiene. La tipología que se ofrece, sustentada en diferentes trabajos (De Haro, 2007; Gonzalez Fernández, s. f.), deja fuera, deliberadamente, los blogs de centro (transmiten solo información) y los blogs de profesores no orientados de forma específica a la docencia. De Haro (2007), dando razones de su definición, lo explica así: “deja fuera los blogs de centro (que normalmente tienen carácter informativo y no educativo), así como muchos blogs escritos por profesores relacionados con la educación, (...), aunque creo que la mayoría de ellos sí son blogs educativos o más exactamente blogs educacionales." (Párr. 7)

Aunque pensada prioritariamente para los blogs de enseñanza no universitaria (primaria, secundaria, bachillerato) esta clasificación puede dar cuenta de los blogs utilizados en la enseñanza superior. Así, dependiendo de quién los implementa y sostiene, tendremos los siguientes tipos de edublogs:

1. EL blog del profesor (blogfesor): edublog creado y gestionado por el docente con el objetivo de mantener actualizados a los alumnos para el adecuado desarrollo de la asignatura, curso o programa que imparte. Así, en él se publicarán reflexiones, contenidos que completan o amplían la materia, instrucciones sobre actividades y proyectos, experiencias de aula, al tiempo que se compartirán recursos (textos, audiciones, vídeos, enlaces) y se resolverán dudas de los estudiantes, etcétera. Este blog puede ser gestionado por un solo profesor, denominándose entonces blog de aula (aulablog) o por varios, en cuyo caso se denomina blog colectivo de profesores. Este edublog puede o no tener interacción a través de los comentarios de los alumnos y con los enlaces a los blogs de los alumnos (blogroll).

2. Edublog del alumno: está elaborado personalmente por el alumno que asume el protagonismo total de la creación, edición y mantenimiento del blog, así como de su diseño. La temática de estos blogs puede ser variada, puesto que en ellos el alumno puede publicar los textos de temas de su interés, así como también poemas y 
canciones propias o ajenas. Pero, además, recogerán -manejando múltiples fuentes y recursos: texto, vídeo, audio y fotografías - el quehacer, actividad y desempeño del alumno en la asignatura. Como subtipos de estos edublogs de alumnos encontramos: el edublog utilizado como portafolio, denominado portafolio de aula, que será un reflejo bastante fiel del desempeño del estudiante en su proceso de aprendizaje, al exhibir, de forma ordenada (por lo general cronológica), un conjunto de trabajos y documentos preseleccionados, en los que el estudiante muestra esfuerzos, logros y progresos en la asignatura, permitiendo la autoevaluación y la evaluación por parte del profesor del proceso de aprendizaje. Cuando el edublog lo elabora un único alumno se denomina blog de alumno, y cuando lo hacen varios: blog colectivo de alumnos. En este caso se asume un modelo docente más innovador, en el que el alumno es el protagonista y el profesor un guía u orientador.

3. Edublog grupal o blog colectivo de aula: sostenido por la actuación mancomunada del conjunto de la clase, aprovechan la capacidad de los blogs de tener múltiples editores y las de enlace con las redes sociales para crear contenidos en forma cooperativa. Es pues de más fácil gestión y mantenimiento. Pueden adquirir la forma de una revista o una publicación periódica. Cuando están elaborados por varios alumnos y profesores se denominan blog colectivo de profesores y alumnos, y cuando lo están por profesores y alumnos de varios centros educativos (como ocurre en la educación preuniversitaria básica y media...), blog colectivo de centros educativos.

\section{Beneficios del edublog en el proceso de ense- ñanza-aprendizaje}

Numerosos son los autores [Martín Montilla y Montilla Coronado (2015); Zambrano Matamala, Rojas Díaz y López Jara Ociel (2017); Pérez-Nevado, Aranda Medina, Hernández León, Martín
González, Benito Bernáldez y Córdoba Ramos (2012); Duart y Lupiáńez (2005); Cabero Almenara, López Meneses y Ballesteros Regaña (2009); Contreras Contreras (2004)] que muestran en sus trabajos las muchas posibilidades que ofrecen los edublogs para mejorar el proceso educativo y cómo, tanto profesores como alumnos, se benefician del uso de estas herramientas comunicativas en los procesos teleformativos.

Coinciden estos autores en señalar cómo favorece la implementación de los blogs en las aulas universitarias, en el marco de un modelo pedagógico constructivista asociativo (aquel que se centra en el alumno y en la construcción del conocimiento y del aprendizaje), el desarrollo de competencias generales o transversales, ya que "el Blog es un recurso útil para conformar entornos virtuales de enseñanza y aprendizaje [de carácter flexible, abierto, interactivo y dinámico] gracias a las múltiples potencialidades que ofrece. (Zambrano-Matamala, Rojas-Díaz, Salcedo-Lagos y López-Jara, 2017, p. 650).

Entre los numerosos beneficios que brindan los edublogs a alumnos y profesores se encuentran los siguientes:

1) Fomenta el aprendizaje colaborativo y autónomo de los alumnos, pudiendo llegar a crear auténticos entornos virtuales de aprendizaje.

2) Amplían los límites espacio-temporales del aula presencial.

3) Favorecen la evaluación y la autoevalución continua de los procesos formativos y de aprendizaje.

4) Proporcionan evidencias sobre el progreso de los estudiantes y retroalimenta el proceso de enseñanza-aprendizaje.

5) Ofrecen al profesor la posibilidad de implementar atractivas y novedosas estrategias metodológicas que van más allá de la rutinaria lección magistral. 
6) Desarrolla las competencias de lectoescritura y de comunicación lingüística.

7) Facilitan el acceso, la asimilación, aprehensión y "construcción" de nuevo conocimiento, tanto individualmente como de forma grupal.

8) Pueden lograr que los alumnos lleguen a convertirse en auténticos expertos en la materia que cursan.

9) Incrementan las capacidades intelectuales de los alumnos.

10) Facilitan los procesos de aprendizaje cognitivo y metacognitivo y la competencia de aprender a aprender y, consecuentemente, la capacidad de seguir aprendiendo toda la vida.

11) Aumentan el interés de los estudiantes en el aprendizaje, abriéndoles cauces efectivos de participación.

12) Son un medio idóneo para coordinar proyectos de investigación en red al permitir organizar la documentación y beneficiarse de la retroalimentación continua de los compañeros.

13) Desarrollan la competencia digital de los estudiantes reduciendo la brecha digital.

Los blogs o edublogs son, pues, como vemos, una valiosa herramienta educativa que enfatiza el aprendizaje por encima de la enseñanza. Molina, Jimeno, Pérez-Samaniego, Devís-Devís, Villamón y Valenciano Valcárcel (2013) señalan, sin embargo, que:

No hay que suponer que el simple hecho de añadirlos en el desarrollo de las asignaturas asegure el éxito pedagógico o la innovación educativa. Como cualquier recurso o proceso educativo, requiere de una evaluación que permita la valoración crítica del mismo, tanto por parte del profesorado como del alumnado. (p. 29)

\section{Conclusiones}

Las Tecnología de la Información y la Comunicación (TIC) han impactado de forma significativamente positiva a las sociedades contemporáneas en todos los ámbitos. La educación, y menos la educación superior, de ningún modo puede ni debe quedar al margen de los beneficios indiscutibles que estas tecnologías, mezcla de la informática con la telemática, pueden aportarle.

Los weblogs son una herramienta de la web 2.0 que permite implementar en las aulas estas versátiles tecnologías de telecomunicación de manera fácil y cómoda, sin apenas gastos o inversiones económicas y sin necesidad de que los alumnos y los profesores necesiten convertirse en expertos en teleinformática.

Nacidos con la Word Wide Web en la década del 2000, los blogs han tenido una gran implantación y popularización, convirtiéndose en una de las redes sociales más utilizadas. Cognitivos, preparados de forma muy particular para la interacción bidireccional y multidireccional (Lozano, 2008, citado por Ruiz Franco y Abella García, 2011), y el intercambio; dialógicos por definición — sin duda una de sus principales características, Duart y Lupiáńez, 2005; Fernández, 2010, citado por Molina Alventosa y Valenciano Valcárcel, 2015-, se encuentran de igual forma dotados de cuantas posibilidades brinda lo digital para soportar textos planos e hipertexto, imágenes, sonido y videos, así como elementos interactivos. Todo ello hace de los blogs, como ya se ha indicado, un poderoso recurso de aprendizaje colaborativo que favorece (refuerza y potencia) el desarrollo de las competencias generales y transversales (competencia comunicativa lingüística, de autonomía e iniciativa personal, competencia para aprender a aprender y competencia digital).

Aun cuando el uso de los blogs se ha dado de forma más notable en la enseñanza preuniversitaria (primaria, secundaria y bachillerato) y bastante menos 
en la enseñanza superior (González Sánchez y García Muiña, 2009), algunas experiencias con estas herramientas virtuales se han desarrollado en universidades españolas y latinoamericanas a lo largo de estos años, siendo los pioneros en su implementación en el mundo hispano las cátedras vinculadas a los estudios de pedagogía y de formación de maestros (Martín Sánchez y Alonso Díaz, 2008; Cabero Almenara, López Meneses y Ballesteros Regaña, 2009).

A nuestro entender, las universidades hispanoamericanas deben sumarse al positivo ejemplo de las anglosajonas, donde, como vimos, primero se implementaron los blogs educativos en sus diferentes modalidades (Martín Montilla y Montilla Coronado, 2015); de igual modo deberían potenciarse, en nuestro ámbito cultural, las investigaciones y análisis en torno a los edublogs y su incidencia en el proceso de enseńanza-aprendizaje en los estudios universitarios, hoy todavía escasos en comparación con los que se han venido realizando en el mundo académico angloparlante (Maenza, 2011). Debemos tener en cuenta que los edublogs, además de su poder cognitivo y de generación de autoaprendizaje, favorecen la inclusión, "son una de las herramientas 2.0 que más fácilmente rompe con las barreras culturales, sociales o económicas, pues solo dependen de la voluntariedad del creador para su generación" (Marín Díaz, Muñoz González y Sampedro Requena, 2014, 117), al tiempo que, como señala Lara (2005), y reitero su señalamiento, "pueden adaptarse a cualquier disciplina, nivel educativo y metodología docente" (p.1), siendo sin duda, dada la enorme capacidad interactiva y colaborativa del blog, en el marco de una pedagogía constructivista donde esta dinámica y versátil herramienta puede encontrar y encuentra su más óptima y eficiente aplicación docente.

\section{Referencias}

Aguaded Gómez, J. I. y López Meneses, E. (2009). La blogsfera educativa: nuevos espacios universitarios de innovación y formación del profesorado en el contexto europeo. REIFOP,
Revista Electrónica Interuniversitaria de Formación del Profesorado, 12(3), 165-172. Recuperado de https:/www.aufop.com/aufop/uploaded_files/ articulos/1254437860.pdf.

Belloch Ortí, C. (s.f.). Las tecnologias de la información y comunicación (T.I.C.).Recuperado de https:/www.uv.es/ bellochc/pdf/pwtic1. pdf.

Cabero Almenara, J., López Meneses, E. y Ballesteros Regaña, C. (2009). Experiencias universitarias innovadoras con blogs para la mejora de la praxis educativa en el contexto europeo. Revista de Universidad y sociedad del Conocimiento (RUSC), 6(2), 1-14. Recuperado de https:// www.researchgate.net/publication/28316886_ Experiencias_universitarias_innovadoras_con_ blogs_para_la_mejora_de_la_praxis_educativa_ en_el_contexto_europeo.

Cabero Almenara, J., López Meneses, E. y Jaén Martínez, A. (2013). Los portafolios educativos virtuales en las aulas universitarias. Instrumentos didácticos para la innovación. Enseñanza \& Teaching. 31(1), 43-70. Recuperado de https://www.researchgate.net/ publication/260636257_Los_portafolios_educativos_virtuales_en_las_aulas_universitarias_Instrumentos_didacticos_para_ la_innovacion_docente_y_la_calidad_de_ los_procesos_de_ensenanza_y_aprendizaje/ download.

Cervera, J. (s.f). Una teoría general del blog. En José M. Cerezo (Dir.), La blogosfera hispana: pioneros de la cultura digital, (10-19). España: Fundación Francés Telecom España. Recuperado de https://www.um.es/campusdigital/ Libros/textoCompleto/varios/la_blogosfera_ hispana.pdf.

Chacón Ortiz, M. (2017). Una experiencia docente de la Web 2.0 mediante el uso de blogs con estudiantes de educación de la Universidad Nacional, Heredia. Diálogos, 11(19), 51-67. Recuperado de https://www.lamjol.info/index. php/DIALOGOS/article/view/5483/5151 
Chávez, M. y Grisolía, M. El uso de Blogs como herramienta para el desarrollo de aprendizajes universitarios. Recuperado de http://www.ufrgs.br/ niee/eventos/RIBIE/2008/pdf/uso_blogs_ herramienta.pdf

Contreras Contreras, F. (2004). Weblogs en educación. Revista Digital Universitaria, 5(10), 1-12. Recuperado de http://www.revista.unam. $\mathrm{mx} /$ vol.5/num10/art65/nov_art65.pdf

De Haro, J. J. (3 de agosto de 2007). Tipos de edublog. [Entrada de un blog], Educativa. Blog sobre calidad e innovación en Educación Secundaria. Recuperado de https://jjdeharo.blogspot. com/2007/08/tipos-de-edublog.html

Delgado, M. L.; Trujillo Torres, J. M.; Lorenzo Martín, R.; Pérez Navío, E. (2011). Usos del weblog en la universidad para gestión de conocimiento y trabajo en red. Pixel-Bit. Revista de Medios y Educación, (39), 141154. Recuperado de http://www.redalyc.org/ pdf/368/36818685012.pdf

Dellepiane, P. A. (s.f.). Blogs en Educación Superior. Una Experiencia en Medios III Informáticos. Recuperado de https://ddd.uab.cat/pub/ $\operatorname{dim} / 16993748 \mathrm{n} 20 / 16993748 \mathrm{n} 20 a 6 . p d f$

Duart, J. M. y Lupiáńez, F. (2005). E-strategias en la introducción y uso de las TIC en la universidad. RUSC. Revista de Universidady sociedad del Conocimiento, 2(1), 5-31. Recuperado de http:// www.redalyc.org/pdf/780/78017141006.pdf

Estalella, A. (s.f.). Yo soy mi blog (y sus conexiones). En José M. Cerezo (Dir.), La blogosfera hispana: pioneros de la cultura digital (pp. 20-37). España: Fundación France Telecom España. Recuperado de https://www.um.es/campusdigital/Libros/textoCompleto/varios/la_blogosfera_hispana.pdf

Fernández Rodicio, C. I. (2010). Innovación educativa en la enseñanza presencial universitaria: utilización de blogs. Innovación Educativa, (20), 167-181. Recuperado dehttps://minerva.usc. es/xmlui/bitstream/handle/10347/5006/13. Fernandez.pdf?sequence $=1$
Fumero, A. (s.f.) Anatomía y fisiología de un blog. En José M. Cerezo (Dir.). La blogosfera hispana: pioneros de la cultura digital, (pp. 198-203). Madrid, España: Fundación France Telecom España. Recuperado de https://www.um.es/ campusdigital/Libros/textoCompleto/varios/ la_blogosfera_hispana.pdf

Gascueña, R. M. (s.f.). La blogosfera, un fenómeno de integración conceptual en el subdominio de internet, 687-685. Recuperado de https://docplayer. es/3391574-La-blogosfera-un-fenomeno-de-integracion-conceptual-en-el-subdominio-de-internet.html

Gewerc Barujel, A. (2005). El uso de weblogs en la docencia universitaria. Revista Latinoamericana de Tecnología Educativa, 4(1), 9-23. Recuperado de https://core.ac.uk/download/ pdf/72044544.pdf

Gómez Villalta, C. (10-11 octubre, 2012). La blogosfera como espacio de investigación. Revisión y caracterización metodológica. Ponencia presentada en El III Congreso Internacional Comunicación 3.0, Salamanca, España. Recuperado de http://campus.usal.es/ - comunicacion3punto0/ comunicaciones/2012/705.pdf

González Fernández, V. R. (s.f). Tema 3.3. los edublogs [página web]. Web 2.0 en Educación. Recuperado de http://platea.pntic.mec.es/ vgonzale/web20_0809exe/tema_33_los_edublog.html

González Sánchez, R. y García Muiña, F. E. (2009). El blog en la docencia universitaria, una herramienta útil para la convergencia europea. Relada (Revista Electrónica de ADA), 3(2). Recuperado de https://abacus.universidadeuropea. es/bitstream/handle/11268/2945/Gonz\%C3\%A1lez\%2c\%20Roc\%C3\%ADo.pdf?sequence $=1 \&$ is Allowed $=y$

Hernández Requena, S. (2008) El modelo constructivista con las nuevas tecnologías: aplicado en el proceso de aprendizaje RUSC. Universities and Knowledge Society Journal, 5(2), 26-35. Recuperado de http:/www.redalyc.org/articulo.oa?id=78011201008 
Internet aula abierta 2.0. Módulo 4. Web 2.0: Blog, wiki y canales de noticias. (s.f.). Elementos de un blog [página web]. Recuperado de http://www.ite.educacion.es/formacion/ materiales/157/cd/m4_1_blog_bitacoras/ elementos_de_un_blog.html

Lara, T. (2005). Blogs para educar. Usos de los blogs en una pedagogía constructivista, 1-23. Recuperado de https://www.researchgate.net/ publication/28109410_Blogs_para_educar_Usos_ de_los_blogs_en_una_pedagogia_constructivista.

López Meneses, E. y Ballesteros Regaña, C. (2008). Caminando hacia el software social: Una experiencia universitaria con blogs. Pixel-Bit. Revista de Medios y Educación. (32), 67-82. Recuperado de https://idus.us.es/xmlui/bitstream/handle/11441/11801/file_1.pdf?sequence=1\&isAllowed $=y$

Maenza, R. R. (2011). Weblogs como recurso educativo universitario. Un modelo de aplicación pensado para universidades argentinas y españolas (tesis de doctorado) Universidad de Salamanca. Salamanca, España. Recuperado dehttps://gredos.usal.es/jspui/bitstream/10366/115629/1/ DDOMI_MaenzaRR_WeblogscomoRecurso.pdf

Manrique Maldonado, K. A. (2015). La web 2.0 y sus servicios como herramientas en el entorno educativo del siglo xxI. RDU: Revista Digital Universitaria, 16(9), 1-13.Recuperado de http://www.revista.unam.mx/vol.16/num9/ art76/art76.pdf

Marín Díaz, V., Muñoz González, J. M. y Sampedro Requena, B. E. (2014). Los blogs educativos como herramienta para trabajar la inclusión desde la Educación Superior. Ensayos, Revista de la Facultad de Educación de Albacete, 29(2) Recuperado de: https://www.google.com/ url? $s a=t \& r c t=j \& q=\& e s r c=s \&$ source $=w e b \& c-$ $\mathrm{d}=1 \& \mathrm{cad}=$ rja\&uact $=8 \& \mathrm{ved}=2$ ahUKEwiuz 4SEtdPjAhVmQt8KHTycCZ8QFjAAegQIAhAC\&url=https\%3A\%2F\%2Fdialnet. unirioja.es\%2Fdescarga $\% 2$ Farticulo\%2F4911699. pdf\&usg=AOvVaw1Vsi39BaGI8M-z_-EV0xSS
Martín Montilla, A. y Montilla Coronado, M. V. C. (2015). El uso del blog como herramienta de innovación y mejora de la docencia universitaria. Profesorado, Revista de Currículum y Formación del Profesorado, 20(3), 659-686. Recuperado de https://recyt.fecyt.es/index. $\mathrm{php} /$ profesorado/article/view/54605/33234

Martín Sánchez, M. A. y Alonso Díaz, L. (noviembre, 2008). Los espacios virtuales de educación: el fenómeno de los edublogs. Ponencia presentada en el I Congreso Virtual Iberoamericano de Calidad en educación a Distancia. Recuperado de http://eduqa2008.eduqa.net/eduqa2008/ images/ponencias/eje_tematico_5/5_75_ Los_espacios_virtuales_Martin_Alonso_ .pdf

Méndez García, C. (febrero, 2005). Los "academic blogs” o bitácoras académicas: ¿Un fenómeno exportable? Ponencia presentada en el $\checkmark$ Congreso Internacional Vitual de Educación. Baleares, Espańa. Recuperado de https:// eprints.ucm.es/32526/1/Documento_completo.pdf

Molina Alventosa, P., Antolín Jimeno, L., Pérez-Samaniego, V., Devís-Devís, J., Villamón, M., y Valenciano Valcárcel, J. (2013). Uso de blogs y evaluación contínua del aprendizaje del alumnado universitario. Edutec. Revista Electrónica de Tecnología Educativa, (43). Recuperado dehttp://www.edutec.es/revista/index.php/ edutec-e/article/view/335/71

Molina Alventosa, P., Valenciano Valcárcel, J. y Valencia-Peris, A. (2015). Los blogs como entornos virtuales de enseńanza y aprendizaje en Educación Superior. Revista Complutense de Educación, 26, 15-31. Recuperado de https:// revistas.ucm.es/index.php/RCED/article/ view/43791/45929

Navarro, V. (2017). Las categorías no son etiquetas. Lo hice y lo entendí. El blog de Vicente Navarro [Entrada de blog], Recuperado de http:// www.vicente-navarro.com/blog/2007/10/29/ las-categorias-no-son-etiquetas/ 
Orihuela, J. L. (2006). La revolución de lops blogs. Cuando las bitácoras se convirtieron en el medio de comunicación de la gente. Madrid, España: La Esfera de los Libros. Recuperado de https://dadun.unav.edu/ bitstream/10171/41323/1/LaRevolucionDeLosBlogs_Orihuela_2006.pdf

Ramírez Sánchez, R. (2010). Concepto, historia y estructura de un weblog. En Samuel Martínez y Edwing Solano (coord.). Blogs, Bloggers, Blogosfera: una revisión multidisciplinaria, (pp. 66-74). México, D.F. México: Universidad Iberoamericana. Recuperado de https://ibero.mx/web/filesd/publicaciones/ blogs-enero2010.pdf

Pérez-Nevado, F., Aranda Medina, E., Hernández León, A., Martín González, A., Benito Bernáldez, M. J. y Córdoba Ramos, M. de G. (2012). Otras actividades complementarias para mejorar la docencia universitaria: elaboración y utilización de blogs. Edutec, (40), 1-12. doi: https://doi.org/10.21556/edutec.2012.40.363.

Real Academia Española (2005). Diccionario panhispánico de dudas. Bogotá, Colombia: Santillana Ediciones Generales.

Ruiz Blanco, S. (2009). Del blog al microblog: El devenir del receptor en generador y emisor de contenidos en la web 2.0 (tesis doctoral). Universidad de Málaga, Málaga, España. Recuperado de http://www.biblioteca.uma. es/bbldoc/tesisuma/17968070.pdf
Ruiz Franco, M. y Abella García, V. (2011). Creación de un blog educativo como herramienta TIC e instrumento TAC en el ámbito universitario. Revista Teoría de la Educación: Educación y Cultura en la Sociedad de la Información. 12(4), 53-70. Recuperado de http://campus. usal.es/ $\sim$ revistas_trabajo/index.php/revistatesi/ article/view/8526/8612

Thiefels, J. (julio 2018). Cómo escribir en un blog para crear el post perfecto. [Entrada de un blog]. Recuperado de https://es.godaddy.com/ blog/como-escribir-en-un-blog-para-crear-elpost-perfecto/

Valero, A. (enero 2007). Cómo escribir un artículo de blog. Apuntes sobre blogs. [Entrada de un blog]. Recuperado de http://avalerofer.blogspot.com/2007/01/cmo-escribir-un-artculode-blog.html

Valero, A. (2009). Creación y uso educativo de blogs. Recuperado dehttp://www.tinglado.net/tic/ avalero/taller_blogs.pdf

Villarejo, A. (enero 2014). 27 consejos para escribir un buen post. Recuperado de https://www. 40defiebre.com/consejos-escribir-post

Zambrano-Matamala, C., Rojas-Díaz, D., Salcedo-Lagos, P. y López-Jara, O. (2018). Percepción de estudiantes de pedagogía sobre la utilidad de los blogs en educación. Revista Electrónica Educare, 23(1), 1-16. doi: http:// dx.doi.org/10.15359/ree.23-1.19

\section{Datos de filiación}

Carlos Enrique Cabrera. Se licenció en Filología Hispánica en la Universidad Autónoma de Madrid (España) y realizó estudios de Bibliotecología y Documentación en instituciones educativas de esa capital europea. Ha publicado Reflexiones de bolsillo (2002); Tiempos dificiles (2010) y Conjuros y otros microcuentos (2013). Es además coautor del libro Español Universitario (Santillana Universitaria, 2006), de la información turística: Ciudad Colonial Santo Domingo (Tando Editora, 2011) y Voces con caudal: Entrevistas y crónicas (2017). 